\title{
Genetic Counseling, Screening and Risk-Reducing Surgery in Patients with Primary Breast Cancer and Germline BRCA Mutations: Unmet Needs in Low- and Middle- Income Countries
}

(1) Hiba A. Moukadem, (1) Ahmad Al Masry, (1) Rula W. Atwani, (10 Firas Kreidieh, (1) Lana E. Khalil, (1) Rita Saroufim, (1) Sarah Daouk, (1) Iman Abou Dalle, (1) Nagi S. El Saghir

Division of Hematology Oncology, Department of Internal Medicine, American University of Beirut Medical Center, Beirut, Lebanon

\begin{abstract}
Objective: Worldwide genetic counseling practices are variable and often not reported in low- and middle-income countries (LMICs). We present the follow-up genetic counseling, breast screening, risk-reducing salpingo-oophorectomy (RRSO) and contralateral prophylactic mastectomy (CPM) in a cohort of study patients with either BRCA pathogenic mutations or BRCA variant of unknown significance (VUS).

Materials and Methods: Chart review and phone calls for the collection of information. Out of a cohort of 250 patients, 14 had deleterious mutations and 31 had a VUS, of whom 19 had primary early breast cancer. We collected information about genetic counseling, screening, CPM and RRSO.

Results: Fourteen patients with deleterious mutations (7 BRCA1 and 7 BRCA2) and 19 patients with VUS mutations (20 VUS, 4 BRCA1, 16 BRCA2; 1 patient had both) were surveyed. Of 14 patients with deleterious BRCA mutations, 57.14\% (8/14 patients) received genetic counseling from their oncologist. Subsequently $85.71 \%$ (12/14) are undergoing mammography screening and 35.71\% (5/14) breast screening magnetic resonance imaging (MRI). Furthermore, $50 \%$ of them underwent CPM and $57.14 \%$ underwent RRSO. Of 19 patients with VUS mutations, $10.5 \%$ received genetic counseling from their oncologist; $78.9 \%$ were undergoing regular screening mammogram and 31.5\% were undergoing breast MRI; one patient underwent CPM and two patients RRSO.

Conclusion: Within three years from knowing they have a mutation, $50 \%$ of patients with germline BRCA mutations had undergone CPM and $60 \%$ RRSO, the majority of them had screening mammography surveillance but only $50 \%$ had screening MRI. Follow-up of patients with VUS with mammography was $78 \%$ but MRI was only $31 \%$. Lack of MRI surveillance reflects both limited resources and insufficient counseling. Genetic counseling was done by medical oncologists, which reflects a trend in LMIC. Our Data shows the importance of the need for professional genetic counselors and optimal surveillance in Lebanon and other LMICs.
\end{abstract}

Keywords: Hereditary breast cancer, genetic counseling, screening; contralateral prophylactic mastectomy, risk-reducing salpingo-oophorectomy, germline BRCA mutation, VUS mutation

Cite this article as: Moukadem HA, Masry AA, Atwani RW, Kreidieh F, Khalil LE, Saroufim R, Daouk S, Dalle IA, El Saghir NS. Genetic Counseling, Screening and Risk-Reducing Surgery in Patients with Primary Breast Cancer and Germline BRCA Mutations: Unmet Needs in Low- and Middle-Income Countries. Eur J Breast Health 2022; 18(1): 16-20

\section{Key Points}

- Optimal care, in terms of prevention and early intervention, is provided by identifying women and their family members who are at high risk of carrying mutations.

- Genetic counseling along with appropriate surveillance and interventions for BRCA mutations are recommended because of the known benefits from surveillance, chemoprevention and breast/ovarian risk reducing surgeries.

- Worldwide, the practice of genetic counseling among women with deleterious BRCA 1 and 2 variants classified as of unknown significance is variable and is limited in most low- and-middle income countries. 


\section{Introduction}

Breast cancer is the most common cancer among women, worldwide $(1,2)$. Hereditary breast cancer accounts for 5 to $10 \%$ of cases, 15 to $20 \%$ of breast cancer cases are familial and 70 to $80 \%$ are sporadic (3). At least $50 \%$ of hereditary breast cancer is due to germline autosomal dominant pathogenic BRCA1 or BRCA2 mutation (4). Breast cancers in patients with $B R C A 1$ mutations are usually of high-grade with rates of triple-negative breast cancer (TNBC) as high as 80 to $90 \%$ (5). Conversely, the rate of BRCA mutation in TNBC ranges between 11 to $35 \%(4,6,7)$. The risk of developing breast cancer in patients who have a BRCA mutation can be as high as $80 \%(40 \%-80 \%)(8)$, while the chance of having ovarian cancer is between 17 to $44 \%$ (9). In terms of prevention and early intervention, breast cancer care is optimized by identifying women and their family members at highrisk of carrying such mutations $(10,11)$. Individuals identified with a variant of unknown significance (VUS) should be counseled based upon their personal and family history, irrespective of the variant $(12,13)$. While recent American Cancer Society guidelines for breast cancer screening among average-risk women call for screening starting at the age of 45 years (14), the European Society of Medical Oncology calls for mammography screening for women aged 50-69 years with a Level $1 \mathrm{~A}$ evidence while leaving it as an option for women in the age groups 40-49 and 70-74 years (15). For early detection in highrisk women and mutation carriers, guidelines call for annual screening with mammogram starting at age 30 years, or 10 years earlier than the first case in the family, along with a yearly breast screening magnetic resonance imaging (MRI), starting at 25 years old $(16,17)$.

Women who are carriers of BRCA1/2 mutation and are newly diagnosed with breast cancer have a $17 \%-37 \%$ risk of developing a contralateral breast cancer within 10 years of their initial diagnosis $(15,16)$. Over $50 \%$ of $B R C A$ mutation carriers opt for contralateral prophylactic mastectomy (CPM), thus decreasing the risk of breast cancer by $90 \%$. Moreover, women with a $B R C A$ variant are also at risk of developing ovarian cancer, ranging from $17 \%$ in $B R C A 2$ to $44 \%$ in $B R C A 1$ carriers, compared to a $2 \%$ risk in women without $B R C A$ variants (18). Many genetic counseling practices are reported in the literature $(19,20)$. risk-reducing salpingo-oophorectomy (RRSO) around the age of 40, usually after completion of family plans, is recommended for women who are BRCA1/2 mutation carriers. This prophylactic surgery reduces the risk of developing breast cancer by $50 \%$ and reduces the ovarian cancer risk by $80 \%-$ $96 \%(21,22)$.

Breast cancer represents $35 \%$ of all cancers affecting women in Lebanon and Arab countries, with a median age of diagnosis of 48-52 years $(23,24)$. We have previously reported the prevalence of $B R C A$ mutations in 250 ethnic Lebanese Arab women with a high risk of having hereditary breast cancer and found that $5.6 \%$ had either $B R C A 1$ or $B R C A 2$ pathogenic mutations (23). Herein, we reported the results of surveillance three years after disclosure of the presence of a mutation to the patients.

\section{Materials and Methods}

Patients previously identified as carrying BRCA deleterious and VUS mutations were included (23). These patients were investigated in terms of follow-up processes, including genetic counseling, screening recommendations and risk reducing surgeries in patients with early breast cancer. The patients were included in the original study for
$B R C A 1$ and $B R C A 2$ mutation and considered at high risk of genetic predisposition if: aged $<40$ years at diagnosis; aged $\leq 50$ years with at least one relative with breast cancer; aged $\leq 50$ years with one relative with ovarian cancer; $\geq 2$ relatives with breast cancer; $\geq 2$ relatives with ovarian cancer; or patient has personal history of breast or ovarian cancer $(25,26)$. No subjects were male.

The initial study plans included surveillance and follow-up of all patients. There was an additional approval by the Institutional Review Board (IRB) of the American University of Beirut Medical Center (IRB ID: IM.NS.06, date: 17.11.2016 and 29.06.2021) to complete clinical and follow up information via phone calls, when necessary. The content of phone conversations was strictly limited as specified by the IRB. Research Fellows conducted patient interviews and chart reviews. Patients were asked three specific questions about: 1) the screening modality used to detect a second primary breast cancer since they were discovered to have $B R C A$ mutation; 2) if any preventive surgical procedure for breast and/or performed during or after treatment for the initial breast cancer; and 3) if they received any advice for genetic counseling for themselves and their families. The data and results were collected and simply analyzed for the processes of genetic counseling, screening, prophylactic CPM and RRSO interventions in this cohort of previously diagnosed patients with breast cancer, with high genetic predisposition according to the inclusion criteria and all of whom harbored either a deleterious or a VUS mutation for BRCA1/2.

\section{Results}

Study Cohort: In total there were 250 women identified from the earlier study who were at high risk of having hereditary BC. Of these $250,14(5.6 \%)$ had deleterious $B R C A 1$ or $B R C A 2$ mutations and 31 (12.4\%) had VUS mutations, of whom 19 had early breast cancer. As reported earlier, $11.2 \%$ of patients were TNBC, and $25 \%$ of patients with TNBC had a BRCA1 mutation (25). All patients with a $B R C A 1$ deletion had triple negative, grade 3, infiltrating ductal breast carcinoma. Of the 19 patients with $B R C A$ VUS mutations, four were VUS BRCA1 and 16 were VUS BRCA2 while one patient had both $B R C A 1$ and BRCA2 VUS detected (24).

Genetic counseling for patients with $B \boldsymbol{R} C A$ deleterious mutations: $57.14 \%$ of patients with BRCA pathogenic mutations said they received genetic counseling. All patients were counseled by their primary oncologist. None received information from a certified genetic counselor.

Genetic counseling for patients with VUS mutations: Only $10.5 \%$ reported having genetic counseling, and again this was only by their managing oncologist.

Screening mammography and MRI of the breasts in BRCA pathogenic mutation carriers: $85.71 \%$ of patients with a $B R C A$ pathogenic mutation reported that they were undergoing regular screening mammography. Only $35.71 \%$ said they were receiving breast screening MRI in addition to yearly mammograms.

Genetic counseling and screening in family members of BRCA1/2 pathogenic or VUS mutations: $57.14 \%$ reported that they had advised their family members (sisters and daughters) to undergo $B R C A$ mutation testing. Furthermore, only $21.0 \%$ of the patients with VUS mutations advised their family members to undergo $B R C A$ mutation testing. 
Mammography and breast MRI in patients with VUS: Regular screening mammograms were consistently and persistently performed in $15(78.9 \%)$ of patients with a VUS. However, only $31.5 \%$ had and continued to get regular screening MRI of the breasts (Graph 1).

Risk reducing surgery in BRCA pathogenic mutation carriers: CPM was done in $50 \%$ of patients and RRSO in $57.14 \%$ of patients with a pathogenic mutation. $50 \%$ of the patients had both CPM and RRSO.

Risk reducing surgery in $\boldsymbol{B R C A}$ VUS mutation carriers: Of the patients with BRCA1/2 VUS mutation, only 5.2\% had CPM and $10.5 \%$ had RRSO (Graph 1). All patients who underwent these surgeries did so at the recommendation of their private oncologist who initiated discussion and counseling with them.

Chemoprevention: Chemoprevention was given for patients with a $B R C A$ mutation in this study. Premenopausal women received tamoxifen, while post-menopausal women had either tamoxifen or aromatase inhibitor (AI). Chemoprevention with tamoxifen was done in $41 \%$ of patients. AI was used in $6 \%$ of patients. Premenopausal patients on $\mathrm{AI}$ also received ovarian function suppression (Goserelin subcutaneous tunnel injection $3.6 \mathrm{mg}$ every 28 days) treatment as part of their adjuvant therapy.

\section{Discussion and Conclusion}

This was a follow-up study in a group of patients with pathogenic and VUS mutations in $B R C A$, identified as part of a study of 250 patients at high risk of having a hereditary breast cancer. In the full cohort the mean germline pathogenic mutation rate was $5.6 \%$, with the highest rate $(10.6 \%)$ in patients below 40 with a positive family history of breast cancer (25). Although the number of patients in the present study is small, we report real world rates of surveillance in patients with $B R C A$ pathogenic and VUS mutations. It is notable that half of $B R C A 1 / 2$ patients underwent contralateral prophylactic mastectomy, which is consistent with the generally reported rate of prophylactic mastectomy, ranging from $29.9 \%$ to $55.4 \%$ (28). A meta-analysis had shown that the risk of contralateral breast cancer is $25 \%$ for $B R C A 1$ carriers and $13.5 \%$ for $B R C A 2$ carriers vs. $3.6 \%$ for non-carriers (29). There has been a recent trend towards prophylactic contralateral mastectomy or bilateral mastectomy at the time of initial breast cancer surgery (30).

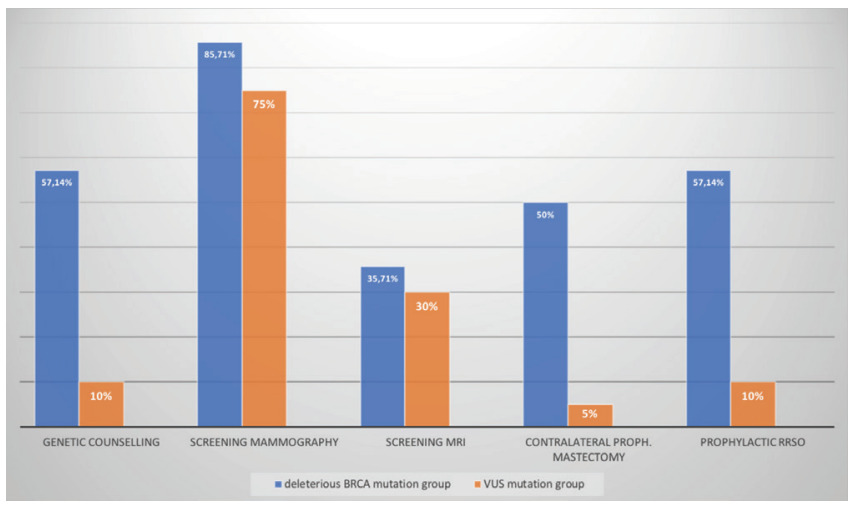

Graph 1. Genetic counseling, screening mammography and MRI, risk reducing surgery in patients with BRCA pathogenic and VUS mutations

MRI: Magnetic resonance imaging, VUS: Variant of unknown significance, BRCA:
Published literature shows that around $56 \%$ of BRCA1/2 patients undergo prophylactic oophorectomy (31). Prophylactic oophorectomy has been shown to reduce the risks of both breast and ovarian cancer by $50 \%$ and $95 \%$, respectively, in women with $B R C A 1$ or $B R C A 2$ mutation. If prophylactic oophorectomy is performed by age 40, breast cancer risk can be also reduced by $56 \%$ and $43 \%$, for BRCA1 and BRCA2 carriers, respectively (32). Once again, our rates of risk reducing prophylactic salpingo-oophorectomy of $57.14 \%$ is consistent with the literature.

Surveillance with MRI alternating with mammography is a recommended option in BRCA1/2 carriers (33-35). In our cohort of patients, more than $80 \%$ with either mutation did undergo screening mammography, but only $25 \%-31 \%$ underwent screening MRI. This is likely due to suboptimal counseling and limited resources.

Genetic counseling together with appropriate surveillance and interventions for patients with $B R C A$ mutations are recommended because of the known benefits from surveillance, chemoprevention and breast/ovarian risk reducing surgery. Availability of professional genetic counseling is variable and it is generally lacking in most LMICs (36-39), and even in many high income countries (HICs) $(10,12)$.

Although the National Comprehensive Cancer Network, US Preventive Services Task Force, and American College of Obstetricians and Gynecologists issued specific guidelines for genetic counseling referral, based on personal and family history including screening for hereditary breast and ovarian cancers, women meeting the criteria for genetic counseling and screening are often not referred (12). In the United States only 50\% of those identified as high risk for carrying a genetic mutation are offered genetic counseling, highlighting the underuse of this type of recommended health care (10). The few published studies show that physicians have a positive attitude towards genetic counseling but lack sufficient knowledge to counsel adequately (13). In Lebanon, as in many other countries, and especially in LMIC, there is a lack of genetic counselors and there are no national guidelines for genetic screening. In addition, genetic counseling is not generally covered by health insurance companies.

Genetic counseling was documented in only about one third of our cohort of patients, and it was mostly done by the patients' own oncologists because of lack of professional counselors and high-risk breast clinics in the country. The 2015 American Society of Clinical Oncology (ASCO) Policy Statement on Genetic and Genomic Testing for Cancer Susceptibility included quality assurance, informed consent, patient privacy, protection from genetic discrimination, public and provider education, and efforts to identify and reduce disparities in access to clinical genetics services (40). These recommendations are based on studies in countries with robust health systems (41). Genetic counseling should be an integral part of these recommendation, not only for LMICs but also in HICs. In HICs, this is because of the now widely available access to genetic testing when there is a requirement for safe and appropriate counseling concerning prognostic and therapeutic information which is not always available from genetic testing service providers $(42,43)$.

As for patients with VUS mutations, most of our cohort underwent screening mammography (78.9\%), but only $31 \%$ had screening MRI. This also reflects both suboptimal counseling and limited resources. As for risk reducing surgery, only one patient had CPM and two had RRSO. This is in line with literature and guidelines, as CPM and 
RRSO are not recommended $(14,40,44)$ unless the patient has a very strong family history and desires to have CPM and/or RRSO.

Follow up of high-risk patients and mutation-carriers is best done at specialized centers and clinics (45). However, in most parts of the world the majority of patients and carriers are followed by their private oncologists, with the exception of patients attending major cancer centers. Genetic counseling is included in the The European Society for Medical Oncology (ESMO)/ASCO Global Curriculum for training of medical oncologists (45). This issue needs a stepwise implementation. Coordination of care between referral cancer centers and general hospitals and general oncologists would help resolve this unmet need and improve surveillance and risk reducing surgeries (12). Professional genetic counselors are urgently needed in most LMICs and worldwide. Education and awareness of oncologists remains important as most patients are followed up by their primary oncologists. The widespread implementation of telemedicine during the coronavirus disease-2019 (COVID-19) era can be used to help $B R C A$ carriers and the high-risk population for breast cancer as online consultations with genetic counselors may become more accessible for patients everywhere including both HICs and LMICs.

In conclusion, in this cohort of women living in the Lebanon, the majority of patients with BRCA1/2 mutations underwent screening mammography but only a minority had breast screening MRI, despite recommendations. Genetic counseling for both the patients and their families was mostly given by medical oncologists. The requirement for optimal screening and genetic counseling is still not met in this cohort. We therefore believe that there remains a need for greater provision of professional genetic counselors and high-risk breast clinics, not only in our own country but also in other LMICs, and even among HICs, globally.

Ethics Committee Approval: This study approved by the Institutional Review Board (IRB) of the American University of Beirut Medical Center (IRB ID: IM.NS.06, date: 17.11.2016 and 29.06.2021).

Informed Consent: Informed consent was obtained.

Peer-review: Externally peer-reviewed.

\section{Authorship Contributions}

Concept: N.S.E.S.; Design: N.S.E.S.; Data Collection and/or Processing: H.A.M., A.A.M., R.W.A., F.K., L.E.K., R.S., S.D., I.A.D., N.S.E.S.; Writing: H.A.M., A.A.M., R.W.A., F.K., L.E.K., R.S., S.D., I.A.D., N.S.E.S.; Critical Review: H.A.M., A.A.M., R.W.A., F.K., L.E.K., R.S., S.D., I.A.D., N.S.E.S.

Conflict of Interest: No conflict of interest declared by the authors.

Financial Disclosure: The authors declare that this study received no financial disclosure.

\section{References}

1. Bray F, Ferlay J, Soerjomataram I, Siegel RL, Torre LA, Jemal A. Global cancer statistics 2018: GLOBOCAN estimates of incidence and mortality worldwide for 36 cancers in 185 countries. CA Cancer J Clin 2018; 68: 394-424. CA Cancer J Clin 2020; 70: 313. (PMID: 30207593) [Crossref]

2. Zaidi Z, Dib HA. The worldwide female breast cancer incidence and survival. Conference: Proceedings: AACR Annual Meeting 2019; March 29-April 3, 2019; Atlanta, GA [Crossref]
3. Apostolou P, Fostira F. Hereditary breast cancer: the era of new susceptibility genes. Biomed Res Int 2013; 2013: 747318. (PMID: 23586058) [Crossref]

4. King MC, Levy-Lahad E, Lahad A. Population-based screening for BRCA1 and BRCA2: 2014 Lasker Award. JAMA 2014; 312: 1091-1092. (PMID: 25198398) [Crossref]

5. Ellsworth DL, Turner CE, Ellsworth RE. A review of the hereditary component of triple negative breast cancer: high- and moderatepenetrance breast cancer genes, low-penetrance loci, and the role of nontraditional genetic elements. J Oncol 2019; 2019: 4382606. (PMID: 31379942) [Crossref]

6. Greenup R, Buchanan A, Lorizio W, Rhoads K, Chan S, Leedom T, et al. Prevalence of BRCA mutations among women with triple-negative breast cancer (TNBC) in a genetic counseling cohort. Ann Surg Oncol 2013; 20: 3254-3258. (PMID: 23975317) [Crossref]

7. Peshkin BN, Alabek ML, Isaacs C. BRCA1/2 mutations and triple negative breast cancers. Breast Dis 2010; 32: 25-33. (PMID: 21778580) [Crossref]

8. Casaubon JT, Grewal US, Regan JP. BRCA 1 and 2. StatPearls. Treasure Island (FL): StatPearls Publishing Copyright (C) 2020, StatPearls Publishing LLC.; 2020. (PMID: 29262038) [Crossref]

9. Kuchenbaecker KB, Hopper JL, Barnes DR, Phillips KA, Mooij TM, Roos-Blom MJ, et al. Risks of breast, ovarian, and contralateral breast cancer for brca1 and brca2 mutation carriers. JAMA 2017; 317: 24022416. (PMID: 28632866) [Crossref]

10. Evers C, Fischer C, Dikow N, Schott S. Familial breast cancer: Genetic counseling over time, including patients' expectations and initiators considering the Angelina Jolie effect. PLoS One 2017; 12: e0177893. doi: 10.1371/journal.pone.0177893. (PMID: 28542378) [Crossref]

11. Chen S, Parmigiani G. Meta-analysis of BRCA1 and BRCA2 penetrance. J Clin Oncol 2007; 25: 1329-1333. (PMID: 17416853) [Crossref]

12. Wood ME, Kadlubek P, Pham TH, Wollins DS, Lu KH, Weitzel JN, et al. Quality of cancer family history and referral for genetic counseling and testing among oncology practices: a pilot test of quality measures as part of the American Society of Clinical Oncology Quality Oncology Practice Initiative. J Clin Oncol 2014; 32: 824-829. (PMID: 24493722) [Crossref]

13. Van Riel E, Wárlám-Rodenhuis CC, Verhoef S, Rutgers EJ, Ausems MG. BRCA testing of breast cancer patients: medical specialists' referral patterns, knowledge and attitudes to genetic testing. Eur J Cancer Care (Engl) 2010; 19: 369-376. [Crossref]

14. Daly MB, Pal T, Berry MP, Buys SS, Dickson P, Domchek SM, et al. Genetic/familial high-risk assessment: breast, ovarian, and pancreatic, version 2.2021, NCCN clinical practice guidelines in oncology. J Natl Compr Canc Netw 2021; 19: 77-102. (PMID: 33406487) [Crossref]

15. Cardoso F, Kyriakides S, Ohno S, Penault-Llorca F, Poortmans P, Rubio IT, et al; ESMO Guidelines Committee. Electronic address: clinicalguidelines@esmo.org. Early breast cancer: ESMO Clinical Practice Guidelines for diagnosis, treatment and follow-up $\dagger$. Ann Oncol 2019; 30: 1194-1220. Erratum in: Ann Oncol 2019; 30: 1674. Erratum in: Ann Oncol 2021; 32: 284. (PMID: 31161190) [Crossref]

16. Bitencourt AG, Rossi Saccarelli C, Kuhl C, Morris EA. Breast cancer screening in average-risk women: towards personalized screening. $\mathrm{Br} \mathrm{J}$ Radiol 2019; 92: 20190660. (PMID: 31538501) [Crossref]

17. Singer CF, Balmaña J, Bürki N, Delaloge S, Filieri ME, Gerdes AM, et al. Genetic counselling and testing of susceptibility genes for therapeutic decision-making in breast cancer-an European consensus statement and expert recommendations. Eur J Cancer 2019; 106: 54-60. (PMID: 30471648) [Crossref]

18. Harmsen MG, Arts-de Jong M, Hoogerbrugge N, Maas AH, Prins JB, Bulten J, et al. Early salpingectomy (TUbectomy) with delayed oophorectomy to improve quality of life as alternative for risk-reducing 
salpingo-oophorectomy in BRCA1/2 mutation carriers (TUBA study): a prospective non-randomised multicentre study. BMC Cancer 2015; 15: 593. (PMID: 26286255) [Crossref]

19. US Preventive Services Task Force, Owens DK, Davidson KW, Krist AH, Barry MJ, Cabana M, et al. Risk assessment, genetic counseling, and genetic testing for BRCA-Related Cancer: US preventive services task force recommendation statement. JAMA 2019; 322: 652-665. Erratum in: JAMA 2019; 322: 1830. PMID: 31429903. [Crossref]

20. Forbes C, Fayter D, de Kock S, Quek RG. A systematic review of international guidelines and recommendations for the genetic screening, diagnosis, genetic counseling, and treatment of BRCA-mutated breast cancer. Cancer Manag Res 2019; 11: 2321-2337. (PMID: 30962720) [Crossref]

21. Domchek SM, Friebel TM, Singer CF, Evans DG, Lynch HT, Isaacs C, et al. Association of risk-reducing surgery in BRCA1 or BRCA2 mutation carriers with cancer risk and mortality. JAMA 2010; 304: 967-975. (PMID: 20810374) [Crossref]

22. Finch AP, Lubinski J, Møller P, Singer CF, Karlan B, Senter L, et al. Impact of oophorectomy on cancer incidence and mortality in women with a BRCA1 or BRCA2 mutation. J Clin Oncol 2014; 32: 1547-1553. (PMID: 24567435) [Crossref]

23. El Khoury CJ, Adib SM, Chaaya M, El Asmar K, Charafeddine M, ElSaghir NS. Trends in breast cancer staging at diagnosis associated with screening campaigns in lebanon. Womens Health Rep (New Rochelle) 2020; 1: 521-528. (PMID: 33786518) [Crossref]

24. El Saghir NS, Khalil MK, Eid T, El Kinge AR, Charafeddine M, Geara $\mathrm{F}$, et al. Trends in epidemiology and management of breast cancer in developing Arab countries: a literature and registry analysis. Int J Surg 2007; 5: 225-233. (PMID: 17660128) [Crossref]

25. El Saghir NS, Zgheib NK, Assi HA, Khoury KE, Bidet Y, Jaber SM, et al. BRCA1 and BRCA2 mutations in ethnic Lebanese Arab women with high hereditary risk breast cancer. Oncologist 2015; 20: 357-364. (PMID: 25777348) [Crossref]

26. BRCA Gene Mutations: Cancer Risk and Genetic Testing. Available from: https://www.cancer.gov/about-cancer/causes-prevention/genetics/ brca-fact-sheet\#q6

27. Warner E. Screening BRCA1 and BRCA2 Mutation Carriers for Breast Cancer. Cancers (Basel) 2018; 10: 477. (PMID: 30513626) [Crossref]

28. Elsayegh N, Webster RD, Gutierrez Barrera AM, Lin H, Kuerer HM, Litton J, et al. Contralateral prophylactic mastectomy rate and predictive factors among patients with breast cancer who underwent multigene panel testing for hereditary cancer. Cancer Med 2018; 7: 2718-2726. (PMID: 29733510) [Crossref]

29. Engel C, Fischer C, Zachariae S, Bucksch K, Rhiem K, Giesecke J, Herold N, et al; German Consortium for Hereditary Breast and Ovarian Cancer (GC-HBOC). Breast cancer risk in BRCA1/2 mutation carriers and noncarriers under prospective intensified surveillance. Int J Cancer 2020; 146: 999-1009. (PMID: 31081934) [Crossref]

30. Yao K, Sisco M, Bedrosian I. Contralateral prophylactic mastectomy: current perspectives. Int J Womens Health 2016; 8: 213-223. (PMID: 27382334) [Crossref]

31. Nair N, Schwartz M, Guzzardi L, Durlester N, Pan S, Overbey J, et al. Hysterectomy at the time of risk-reducing surgery in BRCA carriers. Gynecol Oncol Rep 2018; 26: 71-74. (PMID: 30364812) [Crossref]
32. Abildgaard J, Ahlström MG, Daugaard G, Nielsen DL, Pedersen AT, Lindegaard B, et al. Mortality and risk of cancer after prophylactic bilateral oophorectomy in women with a family history of cancer. JNCI Cancer Spectr 2018; 2: pky034. doi: 10.1093/jncics/pky034. (PMID: 31360861) [Crossref]

33. Teoh V, Tasoulis MK, Gui G. Contralateral prophylactic mastectomy in women with unilateral breast cancer who are genetic carriers, have a strong family history or are just young at presentation. Cancers (Basel) 2020; 12: 140. (PMID: 31935898)

34. van den Broek AJ, van 't Veer LJ, Hooning MJ, Cornelissen S, Broeks A, Rutgers EJ, et al. Impact of Age at Primary Breast Cancer on Contralateral Breast Cancer Risk in BRCA1/2 Mutation Carriers. J Clin Oncol 2016; 34: 409-418. (PMID: 26700119) [Crossref]

35. Valachis A, Nearchou AD, Lind P. Surgical management of breast cancer in BRCA-mutation carriers: a systematic review and meta-analysis. Breast Cancer Res Treat 2014; 144: 443-455. (PMID: 24567198) [Crossref]

36. Anglian Breast Cancer Study Group. Prevalence and penetrance of BRCA1 and BRCA2 mutations in a population-based series of breast cancer cases. Anglian Breast Cancer Study Group. Br J Cancer 2000; 83: 1301-1308. (PMID: 11044354) [Crossref]

37. Papelard H, de Bock GH, van Eijk R, Vliet Vlieland TP, Cornelisse CJ, Devilee P, et al. Prevalence of BRCA1 in a hospital-based population of Dutch breast cancer patients. Br J Cancer 2000; 83: 719-724. (PMID: 10952774) [Crossref]

38. Prince A, Pal T Radford C, Vadaparampil S. Practical considerations in the delivery of genetic counseling and testing services for inherited cancer predisposition. Community Oncol 2013; 10: 147-153. [Crossref]

39. Hafeez Bhatti AB. Discussing genetic testing with patients with breast cancer in developing countries: should we be judicious? J Clin Oncol 2015; 33: 4232-4233. (PMID: 26371136) [Crossref]

40. Robson ME, Storm CD, Weitzel J, Wollins DS, Offit K; American Society of Clinical Oncology. American Society of Clinical Oncology policy statement update: genetic and genomic testing for cancer susceptibility. J Clin Oncol 2010; 28: 893-901. (PMID: 20065170) [Crossref]

41. Ginsburg O, Brennan P. Genetic testing for breast cancer in the era of multigene panels: can we make an impact on population Health? J Clin Oncol 2018; 36: 2817-2819. (PMID: 30130156) [Crossref]

42. Pasick RJ, Joseph G, Stewart S, Kaplan C, Lee R, Luce J, et al. Effective referral of low-income women at risk for hereditary breast and ovarian cancer to genetic counseling: a randomized delayed intervention control trial. Am J Public Health 2016; 106: 1842-1848. (PMID: 27552275) [Crossref]

43. Venetis MK, MacGeorge EL, Baptiste DF, Mouton A, Friley LB, Pastor $\mathrm{R}$, et al. Social network, surgeon, and media influence on the decision to undergo contralateral prophylactic mastectomy. Am J Clin Oncol 2018; 41: 519-525. (PMID: 27465657) [Crossref]

44. Cadiz F, Kuerer HM, Puga J, Camacho J, Cunill E, Arun B. Establishing a program for individuals at high risk for breast cancer. J Cancer 20131; 4: 433-446. (PMID: 23833688) [Crossref]

45. Mateo J, Chakravarty D, Dienstmann R, Jezdic S, Gonzalez-Perez A, Lopez-Bigas N, et al. A framework to rank genomic alterations as targets for cancer precision medicine: the ESMO scale for clinical actionability of molecular targets (ESCAT). Ann Oncol 2018; 29: 1895-1902. (PMID: 30137196) [Crossref] 